\title{
Social Predictors of HIV-testing Among Malaysian Individuals at Higher Risk of HIV Infection
}

\author{
Davood Mehrabi ${ }^{1, ~ *}$, Ezhar Tamam², Hamisah Hasan², Jusang Bolong ${ }^{2}$ \\ ${ }^{1}$ Department of Cultural Studies and Communication, Institute of Humanities and Cultural Studies, Tehran, Iran \\ ${ }^{2}$ Department of Communication, Faculty of Modern Languages and Communication, Universiti Putra Malaysia, Serdang, Selangor, Malaysia
}

Email address:

d.mehrabi@ihcs.ac.ir(D. Mehrabi)

\section{To cite this article:}

Davood Mehrabi, Ezhar Tamam, Hamisah Hasan, Jusang Bolong. Social Predictors of HIV-testing Among Malaysian Individuals at Higher Risk of HIV Infection. International Journal of Science, Technology and Society. Vol. 9, No. 2, 2021, pp. 55-61.

doi: $10.11648 /$ j.ijsts.20211002.13

Received: September 23, 2020; Accepted: October 9, 2020; Published: March 12, 2021

\begin{abstract}
Willingness to test for HIV is initial critical factor to break HIV transmission cycle. This study determined social predictors of willingness for HIV-testing among Malaysians at higher risk of HIV infection. A cross-sectional survey involving 369 individuals at higher risk of HIV was conducted in the Klang Valley, Malaysia. The study used a combination of snowball and respondent-driven sampling methods to approach 456 individuals yielded a response rate of $80.9 \%$. Data were analysed using logistic regression. Almost one third (35.2\%) of the respondents were willing to test for HIV. The odd ratios suggest that the odds of estimating correctly who is willing to take HIV-testing improve by $89 \%$ if one knows the subject's level of HIVrelated self-stigma, by $11 \%$ if one knows the subject's level of HIV knowledge, and by $6 \%$ if one knows the subject's age. Successful intervention programs to increase HIV testing willingness among individuals at higher risk of HIV infection is contingent upon the subjects' HIV-related self-stigma, knowledge about HIV and age. The role of HIV-related self-stigma is more prominent to prevent individual at higher risk of HIV exposure from HIV testing. Further research is needed to investigate social context-specific predictors of HIV-related self-stigma.
\end{abstract}

Keywords: HIV-testing, At-risk Individuals, Health, Social Predictors, Malaysia

\section{Introduction}

Recent Malaysia AIDS Council Report showed that female sex workers (FSWs), injecting drug users (IDUs), men who have sex with men (MSM) and transgender individuals (TGs) account for the rise in new HIV cases in Malaysia [1]. Accordingly, the National Strategic Plan (NSP) for Ending AIDS 2016-2030 laid the foundation to control the spread of HIV among individuals at higher risk of HIV [2] through various initiatives including efforts to increase willingness to test for HIV. To this end, one of the fundamental steps is to identify predictors of willingness for HIV testing. HIV testing is 1) the only way to know somebody's HIV status, 2) a major step for HIV prevention programmes and accessing for health care services, and 3) effective in slowing the spread of the infection if the affected individuals are aware of their serological status as early as possible. Despite the importance of HIV-testing and accessibility testing services, HIV-testing among individuals at higher risk of HIV infection remains a challenge [3].

Past studies have shown that intention for HIV testing is affected by a number of factors such as HIV knowledge, attitudes towards HIV, attitudes towards people living with HIV (PLWH), self-esteem, HIV-related stigma, and perceived social support from friends and family members. According to the theory of planned behavior (TPB) that has been extensively used in health behavioral studies [4-6], intention is a function of attitudes, subjective norms, and perceived behavioural control. Drawing from the theory's postulates relating intention with attitudes, it is assumed that individuals at-risk of HIV infection who have more negative attitudes towards HIV-testing are more likely to have lower willingness for HIV testing. Negative attitudes have been found to correlate with a number of behavioural outcomes. Savaser [8], for instance, found that negative attitudes towards HIV and PLWH may lead to behaviour such as avoiding HIV-testing, giving up hopes, committing suicide and ostracizing family members. In addition to attitude, the 
theory also asserts that subjective norm is a predictor of behavioural intention. However, there are scholars who argue that perceived social support is a better predictor than subjective norm to predict behavioural intention [7]. Applied in HIV testing context, one is more likely to go for HIVtesting, if they believe that they get social support from significant others. Wang, Li, and Zheng [6] and Kagee [9] reported that individuals who found that they were infected with HIV are able to cope with the bad news knowing that the surrounding people will not isolate or discriminate them. Performing a particular behaviour also depends on how easy or difficult the performance of the behaviour is [8]. The TPB included perceived behavioural control (PBC) to account for additional variance in predicting behavioural intentions and behaviours that are not completely under individuals' volitional control [8]. PBC is usually measured by asking people how much control they have over performance of a behaviour (e.g. making a decision for HIV testing is easy or difficult for me). Ajzen [8] and Kagee [9] argued that PBC is comparable with Bandura's concept of self-efficacy. Selfefficacy and self-esteem are similar concepts [10]. Therefore, we measure social support instead of subjective norms and self-esteem instead of PBC. Three other variables including age, HIV knowledge and HIV-related self-stigma added to conceptual framework of this study formulated based on the TPB. HIV-related self-stigma acts as an obstacle to use HIV healthcare services [2], and prevent people to go for HIV testing [11-14]. According to the TPB and informed by the literature review, age and knowledge, as background factors of the TPB, do not directly affect intention but rather have an impact through beliefs and other determinants of the theory.

The proposed model was formulated to find out how much variance in the HIV-testing is explained by age, HIV knowledge, attitudes towards HIV-testing, self-esteem, HIVrelated self-stigma, perceived social support from friend, family members and a special person.

\section{Methods}

\subsection{Data}

This cross-sectional survey was conducted in the Klang Valley, Malaysia. Data were gathered from 369 individuals at higher risk of HIV infection (aged 18-49 years, $M=31.83$, $S D=8.27)$. The study used a combination of snowball and respondent-driven sampling methods to approach 456 individuals yielded a response rate of $80.9 \%$. The first step in sampling was collaborating with NGOs working with the individuals in order to recruit initial participants known as 'seeds'. Seeds were selected based on their potential to recruit at least two other peers to participate in the study. After completing the questionnaire, the 'seeds' were given a small sum of money as incentive for the time spent on the questionnaire. They were also given coupons to encourage them to suggest two other potential participants for inclusion in the study. Each seed was limited to two coupons so that a wide group of subjects could be recruited. The 'seeds' received an additional payment for each recruited participant who completed the questionnaire. An ethical clearance was secured from the Medical Research Ethics Committee of Faculty of Medicine and Health Science, Universiti Putra Malaysia for the survey.

A self-administered questionnaire consisted of 91 questions was employed. The original language of the questionnaire was English. It was then translated into Bahasa Malaysia (Official language in Malaysia). The translated version was verified by language experts to ensure that the Bahasa Malaysia version is equivalent to the English version and the translation was accurate. It took 15 to 20 minutes for the respondents to fill out the questionnaire.

\subsection{Measures}

Items to measure the variables under investigation were adopted from previous studies. Attitude towards HIV testing was measured using 20 items adopted from Muturi and An [15], Green [16] and Paruk and Mohamed [17]. Cronbach's Alpha for attitudes towards HIV-testing was .85.

Perception of social support was measured using the Multidimensional Scale of Perceived Social Support-MSPSS [18]. The scale assessed perceives availability of social support across family members, friends and a special person. Cronbach's Alpha for the perceived social support scale was .93.

Self-esteem was measured with ten items adopted Wright's validated and shortened 10-items Self-Esteem scale [19]. Self-esteem's Cronbach's Alpha was .71. To measure HIVrelated self-stigma, HIV Stigma Scale was adopted [20]. Cronbach's Alpha for the HIV-related self-stigma scale was .90 .

All scales were a 7-point scale, in which respondents were asked to indicate their level of agreement/disagreement to the Likert-items. The response options ranges from (1) strongly disagree to (7) strongly agree. Mean scores of these variables were computed by dividing the total scores by the number of items of the respective variables in which lower mean scores indicate unfavourable attitude, low perceived social support, low self-esteem and low self-stigma. The mean score of 4 is considered as neutral and higher mean scores suggest favourable attitude, high perceived social support, high selfesteem and high self-stigma.

HIV knowledge was assessed with 22 items adopted from Nachega, Lehman [21], Savaser [22], Maimaiti, Shamsuddin [23]. The response options were "YES" and "NO", with correct response given a score of 1 and incorrect a score of 0 . The scores were added to yield a single aggregated knowledge score ranging from 0 to 22 . Zero means there is no knowledge about HIV. Aggregated scores from 1 to 22 were divided into three categories: 1 to 7 consider poor, 8 to 15 indicate moderate and 16 to 22 suggest good level of HIV knowledge.

\section{Results}

The demographic profile of participated individuals is provided in Table 1. Almost half of the respondents (46.3\%) were males, about $37 \%$ were females and the rest $(16.6 \%)$ 
were transgender individuals. In terms of religion, $43.8 \%$ were Muslims, 25.5\% were Christians, $16.3 \%$ were Hindus and $14.4 \%$ belonged to other religions. Regarding employment status, slightly more than one-third of the respondents were employed (34.9\%) and less than two-third $(63.2 \%)$ were unemployed. In terms of knowing a health care facility for free HIV test, $66.4 \%$ did not know such health care facility and $33.1 \%$ knew about such facility. In relations to be a member of any HIV/AIDS-related organization or group, a majority of the respondents $(85.1 \%)$ were not a member of HIV/AIDS related organization or group. Half of the respondents knew someone infected with HIV. More than half of the respondents $(57.5 \%)$ considered themselves not being at HIV risk and $42.5 \%$ reported that they are at risk of HIV infection.

Table 1. Distribution of Respondents' Profile $(n=369)$.

\begin{tabular}{|c|c|c|c|}
\hline & & Frequency & Percentage \\
\hline \multirow{3}{*}{ Gender } & Male & 171 & 46.3 \\
\hline & Female & 137 & 37.1 \\
\hline & Transgender & 61 & 16.6 \\
\hline \multirow{3}{*}{ Religion } & Christian & 94 & 25.5 \\
\hline & Hindu & 60 & 16.3 \\
\hline & Others & 53 & 14.4 \\
\hline \multirow[t]{2}{*}{ Employed Status } & No & 233 & 63.2 \\
\hline & No Answer & 7 & 1.9 \\
\hline \multirow{3}{*}{ Knowing a health care facility to be tested for HIV free of cost } & No & 245 & 66.4 \\
\hline & Yes & 122 & 33.1 \\
\hline & No Answer & 2 & 00.5 \\
\hline \multirow{3}{*}{ Being a member of any HIV/AIDS-related organization or group } & No & 314 & 85.1 \\
\hline & Yes & 53 & 14.4 \\
\hline & No Answer & 2 & 00.5 \\
\hline \multirow[t]{2}{*}{ Knowing someone with HIV } & Yes & 182 & 49.3 \\
\hline & No Answer & 4 & 1.1 \\
\hline \multirow{2}{*}{ Being at HIV risk } & No & 212 & 57.5 \\
\hline & Yes & 157 & 42.5 \\
\hline \multirow{2}{*}{ Willingness to test for HIV } & No & 239 & 64.8 \\
\hline & Yes & 130 & 35.2 \\
\hline
\end{tabular}

Descriptive statistics of the predictors and outcome variables are provided in Table 2 . The average age of the respondents was 31.8 with a standard deviation of 8.27 . The respondents had good knowledge of HIV $(M=14.7, S D=2.9)$, such as HIV causes, transmission, prevention and difference between HIV and AIDS. On attitudes towards HIV testing, we found favorable attitudes $(M=4.32, S D=1.12)$ suggesting that the respondent are more willingness to test for HIV. As shown in the table, almost two third (35.2\%) of the respondents were willingness to test for HIV. The respondents also received higher social supports from a "special person". A higher mean of perceived support from a "special person" $(M=4.64, S D=$ 1.57) compared to that of support from friends $(M=4.60, S D=$ $1.38)$ and family members $(M=3.91, S D=1.70)$ suggests that perceived social supports was greater from a "special person" compared to friends and family members. As evident is the mean scores $(M=4.09, S D=.94)$, the respondents also had neither a high nor a low self-esteem. The results showed that the respondents had high mean scores of HIV-related selfstigma $(M=5.23, S D=1.26)$.

Table 2. Mean and Standard Deviation of predictor variables $(n=369)$.

\begin{tabular}{|c|c|c|c|}
\hline Variables & Min - Max & Mean & Standard Deviation \\
\hline Age & $18-61$ & 31.83 & 8.27 \\
\hline HIV knowledge** & $7-20$ & 14.7 & 2.9 \\
\hline Attitude towards HIV-testing* & $1-7$ & 4.32 & 1.12 \\
\hline Perceived support from family members* & $1-7$ & 3.91 & 1.70 \\
\hline Perceived support from friends* & $1-7$ & 4.60 & 1. 38 \\
\hline Perceived support from a special person* & $1-7$ & 4.64 & 1.57 \\
\hline Self-esteem* & $2.4-5.9$ & 4.09 & .94 \\
\hline
\end{tabular}

**HIV knowledge assessed with 22 items yielded an aggregated score from 0 to 22 that higher mean indicates more HIV knowledgeable.

*All variables measured on a seven-point scale that higher mean scores indicate favourable attitudes, higher perceived social support, self-esteem and selfstigma.

As a preliminary step to run logistic regression, correlation coefficients between the predictors and outcome variable was tested to see if there is any correlation between these variables, to give some ideas which variables may or may not be included in the model, and to provide some ideas to expect the strength of model that this study comes up with. Table 3 
presents the results of correlation coefficients analyses. HIVrelated self-stigma was the highest correlated predictor with willingness to test for $\operatorname{HIV}(\mathrm{r}=-.495, p=.00)$. The next high correlated variables were age $(\mathrm{r}=.308, p=.00)$, followed by social support from family members $(\mathrm{r}=.224, p=.00)$, knowledge about HIV $(\mathrm{r}=.159, p=.00)$, and attitudes towards HIV-testing $(\mathrm{r}=.139, p=.02)$. The higher correlation coefficient indicates the variables are potentially better predictors of outcome variable. As shown in Table 3, social support from friends $(\mathrm{r}=.054, p=.29)$, self-esteem $(\mathrm{r}=.042$, $p=.42)$, and social support from a special person $(\mathrm{r}=.005$, $p=.92)$ were not significantly correlated with willingness to test for HIV.

Table 3. Correlation Coefficient of the Predictor Variables with HIV-testing among individuals at higher risk of HIV infection $(n=369)$.

\begin{tabular}{lll}
\hline & HIV-testing & $\boldsymbol{P}$ \\
\hline Variables & $\boldsymbol{r}$ & .00 \\
\hline HIV-related self-stigma & -.495 & .00 \\
Age & .308 & .00 \\
Social support from Family members & .224 & .00 \\
Knowledge about HIV & .159 & .02 \\
Attitudes towards HIV-testing & .139 & .29 \\
Social support from friends & .054 & .42 \\
Self-esteem & .042 & .005 \\
Social support from Special person & .005 & .92 \\
\hline
\end{tabular}

Logistic regression was used to assess whether or not an individual at higher risk of HIV infection is willing to test for HIV. Preliminary analyses were conducted to ensure that there was no violation of the assumption for collinearity and outliers. Using "Enter" method, the eight predictor variables entered in the model in one single step.

Table 4 presents the results of logistic regression analysis. When all eight variables are considered together, they significantly predict an individual's willingness to test for HIV, Chi square $\left(x^{2}\right)=115.14, d f=7, p<.001$. For the final output model, p-value, odds ratio, standard error and regression coefficients (Beta coefficient) are reported. As table 4 shows, HIV-related self-stigma, HIV knowledge and age of the respondents are significant determinants of willingness to test for HIV. This indicates HIV-related selfstigma, HIV knowledge and age are significant predictors of willingness to test for HIV. The sign of beta coefficients for HIV-related self-stigma (-.110) showed that the variable is negatively associated with willingness to test for HIV. The positive sign of both HIV knowledge (.104) and age (.060) indicated that there is a positive relationship between these two variables with willingness to test for HIV. As table 4 presents, the odd ratios suggest that the odds of estimating correctly who is willing to take HIV-testing improve by $89 \%$ if one knows high risk individual's HIV-related self-stigma, by $11 \%$ if one knows high risk individual's HIV knowledge and by $6 \%$ if one knows high risk individual's age. Attitudes towards HIV-testing, social support from family members, social support from friends, social support from a special person and self-esteem were not a significant predictor of willingness to test for HIV.

Table 4. Logistic Regression Predicting Who is Willing to Take HIV-testing.

\begin{tabular}{llll}
\hline Variable & B & SE* & Odds ratio \\
\hline Constant & 1.406 & 1.753 & 4.08 \\
HIV-related self-stigma & -.110 & .016 & .89 \\
HIV knowledge & .104 & .050 & 1.11 \\
Age & .060 & .018 & 1.06 \\
Attitudes towards HIV-testing & .028 & .032 & .000 \\
Social support from Special person & .005 & .028 & .037 \\
Social support from Family members & .031 & .023 & .00 \\
Social support from friends & -.023 & .030 & .03 \\
Self-esteem & -.004 & .017 & .997 \\
\hline
\end{tabular}

Chi square $\left(\mathrm{x}^{2}\right)=115.14, \mathrm{df}=7, \mathrm{p}<.001$.

*Standard Error.

After excluding the non-significant variables, the final regression model predicting willingness to test for HIV is:

$$
\log [\mathrm{P} /(1-\mathrm{P})]=\beta 0+\beta_{1} \mathrm{X}_{1}+\beta_{2} \mathrm{X}_{2}+\mathrm{B}_{3} \mathrm{X}_{3}+\mathrm{e}=1.406+.060(\text { age })+.104(\mathrm{HIV} \text { knowledge })+-.110(\mathrm{HIV} \text { - related self-stigma })
$$

\section{Discussion and Conclusions}

While the main aim of the present study sought to determine social predictors of HIV testing among individuals at higher risk of HIV infection in Malaysia cultural context, the findings also clearly show that denial of risk of HIV among the high-risk individuals is quite prevalent. This is evident from the findings that 6 out of 10 individuals think that they are not at risk of infecting HIV. These findings are in line with Malaysia's Integrated Biological and Behavioral Survey 2014 (24) that found understanding on prevention of 
HIV through sexual transmission and rejecting major misconceptions about HIV transmission among the individuals was not satisfactory. These indicate that fulfilling Malaysia National Strategic Plan's goal to reach 90 per cent of the individuals tested for HIV by 2020 and 95 per cent by 2030 needs more efforts (2).

As it was found, only 4 out of 10 individuals at higher risk of HIV infection were willing to take HIV test. These findings are inconsistent with those of previous studies. For instance, Batona et al. [3] reported a strong intention to HIV test among a big portion of female sex workers (FSWs) in Benin. Findings of another study [25] conducted in the US reported that almost three quarter of young men who have sex with men were likely (either somewhat, very or likely) to test for HIV. As willingness to take HIV test is still a major barrier among the individuals to come forward for HIV testing, this suggests that despite of progress in achieving previous Malaysia's national strategic plans, challenges in key areas such as need for scaling up HIV testing among the individuals at higher risk of HIV infection need to be addressed (2).

Knowing social determinants of HIV testing is a key step to help increasing HIV-test rates. As evidenced, HIV-related self-stigma identified as the highest negative correlation coefficients with willingness to test for HIV. Negative and significant relationship between HIV-related self-stigma and willingness to test for HIV suggests reducing self-stigma can likely increase people's willingness to engage in HIV testing $[26,27]$. Previous studies [27] reported that a project in Uganda focusing on stigma reduction and changing community norms to increase HIV testing, led to a four-fold increase in HIV testing compared to the control communities. In Malaysia where for the first time in 2014, Stigma Index was included in Integrated Biological and Behavioral Survey (IBBS) (24) among individuals at higher risk of HIV infection, it was found a high level of self-stigma among the individuals. This finding is consistent with the current study that found the respondents had high mean scores of HIVrelated self-stigma. This indicates that reducing HIV-related self-stigma needs to seriously be addressed among the individuals in this country.

Age, social support from family members, HIV knowledge and attitudes towards HIV-testing were the other correlated predictor variables with willingness to test for HIV. Regarding social support from family members, Povey et al. [5] argued when social supports are available, individuals are more likely to perform an intended behavior. In this sense, perception of availability and quality of social support from family members might affect the willingness to test for HIV. Consistent with this study, Malaysia's Integrated Biological and Behavioral Survey [24] found that majority of individuals at higher risk of HIV infection did not significantly experienced stigma and discrimination in familial and community interactions. These supports the findings of a study by Maman, van Rooyen, and Groves [28] who found that people living with HIV prefer to disclose their HIV status to their family members, because they felt that there was nothing more important than getting family support. Previous studies [29-31] have also shown the facilitating role of perceived social support from friends, family members and relevant organizations to increase HIVtesting. Although the inclusion of social support within the TPB literature is relatively new, its stronger influence than subjective norms led to suggestion that social support should be a permanent construct within the TPB, or even replace subjective norms [7]. The current study recommends the inclusion of social support to increase willingness for HIV testing and the other major health and social issues associated with the HIV epidemic.

Our findings indicate that HIV-related self-stigma, knowledge of HIV and age significantly contributed to predict willingness to test for HIV. HIV-related self-stigma that found to be a major predictor of HIV-testing was profound among the individuals. This suggests the urgent need to create self-stigma reduction programs to increase willingness to test among younger individuals at higher risk of HIV infection. Increasing knowledge about HIV is also an initial step to cope with self-stigma. As HIV knowledge was significantly associated with willingness to test for HIV and entered the final model, it implies that HIV knowledge is a major step to increase willingness to test for HIV. Positive relationship between age and willingness to test for HIV also indicates that as people getting older they are more likely to be tested for HIV. Similarly, Young et al. [27] found that older people were more likely to be tested. This finding is crucial, because a substantial number of new HIV infection (34\%) in Malaysia belonged to the 13 to 29 years-old group [1].

As HIV testing considers an entry point for HIV prevention and using care services [3], increasing willingness to test for HIV among individuals at higher risk of infection in Malaysia as a crucial measure can lead to early diagnosis of HIV infection. Early detection helps to start treatment sooner, leading to better health outcomes, longer lives, and reducing the risk of spreading HIV to others. It may eventually help to break HIV transmission cycle.

To our knowledge, this is the first study conducted among individuals at higher risk of HIV infection in Malaysia using the TPB to identify social determinants of HIV testing. Previous published studies also applied the TPB among FSWs [3] or other groups [32]. These studies found a substantial variance of HIV testing explained by the theory. In Malaysia, most previous published studies focusing on HIV-related issues (e.g. 33) were not informed by any particular theories. These studies mainly either identify demographic characteristics and correlates of the uptake of HIV testing, willingness to be tested or barriers in HIV/AIDS prevention programs. Despite differences in various groups being studied, methodological and theoretical approaches, there are some similarities such as lack of willingness to be tested for HIV or no intention of getting an HIV test and lowrisk perception between our findings and previous studies conducted in Malaysia $(33,24)$ regarding willingness for HIV testing. 
Despite its important findings, this study has several limitations include self-reported measurements and crosssectional design of the study that need to be noted. Selfreported measurements may yield to some biased responses. In spite of these limitations, there is no doubt that this crosssectional study contributed to an understanding of the correlations of willingness to test for HIV that are required to create relevant and evidence-based interventions focusing on increasing HIV-testing rate. Furthermore, generalizability is limited and the findings may not be generalized to other individuals at higher risk of HIV infection living in the country.

In terms of practical implications, interventions to increase HIV-testing may need to take a variety of approaches. First, interventions may require focusing on reducing self-stigma surrounding HIV, promoting public awareness about benefits of HIV testing and increasing knowledge about HIV. Second, the strategies need to be implemented as early age of at-risk individuals as possible. The need to promote HIV testing among those less than 25 years highlighted in previous studies [34]. Finally, studying each subgroup of individuals at higher risk of HIV infection separately is crucial. It may assist to capture every nuance differences of at-risk individuals' willingness to test for HIV.

\section{Competing Interests}

Authors have declared that no competing interests exist.

\section{Authors' Contributions}

This work was carried out in collaboration between all authors.

\section{Ethical approval}

This study had approval of the Research Ethics Committee of Universiti Putra Malaysia (reff.:upm/fpsk/100-9/2-jkeupm (fbmk_nov (12) 21).

\section{Acknowledgements}

This research (Project no.: GP-IPS/2013-9395200) was funded by the Putra Research Grant of University Putra Malaysia.

\section{References}

[1] Malaysian AIDS Council and Malaysian AIDS Foundation (2016). Snapshot of HIV/AIDS in Malaysia 2016. Available from: https://www.mac.org.my/v3/wpcontent/uploads/2017/11/Snapshot-of-HIV-AIDS-inMalaysia-2016_Brochure_31072017-Web.pdf.

[2] Ministry of Health (2015a), Malaysia National Strategy Plan for Ending AIDS 2016 - 2030. Available from: http://www.aidsdatahub.org/sites/default/files/publication/Mal aysia_National_strategic_plan_2016-2030.pdf
[3] Batona G, Gagnon MP, Simonyan DA, Guedou FA, Alary M (2015). Understanding the intention to undergo regular HIV testing among female sex workers in Benin: a key issue for entry into HIV care. J Acquir Immune Defic Syndr. 68 (Suppl 2): 206-12.

[4] Deacon H (2006). Towards a sustainable theory of healthrelated stigma: lessons from the HIV/AIDS literature. Journal of Community \& Applied Social Psychology. 16 (6): 418-425.

[5] Povey R, Conner M, Sparks P, James R, Shepherd R (2000). The theory of planned behaviour and healthy eating: Examining additive and moderating effects of social influence variables. Psychology \& Health. 14 (6): 991-1006.

[6] Wang Y, Li B, Zheng J, et al. (2009). Factors related to female sex workers' willingness to utilize VCT service: a qualitative study in Jinan city, northern China. AIDS Behav. 13 (5): 866872 .

[7] Hamilton K, White KM (2008). Extending the Theory of Planned Behavior: The Role of Self and Social Influences in Predicting Adolescent Regular Moderate-to-Vigorous Physical Activity. Journal of Sport \& Exercise Psychology. 30 (1): p. 56-74.

[8] Ajzen I, (1991). The theory of planned behavior. Organizational Behavior and Human Decision Processes. 50: 179-211.

[9] Kagee, A, (2008). Adherence to antiretroviral therapy in the context of the national roll-out in South Africa: Defining a research agenda for psychology. South African Journal of Psychology. 38 (2): 413-428.

[10] Judge TA, Erez A, Bono JE, Thoresen CJ (2002). Are measures of self-esteem, neuroticism, locus of control, and generalized self-efficacy indicators of a common core construct? Journal of Personality and Social Psychology. 83 (3): 693-710.

[11] Huang, M. and Mohd Nasir Mohd Taib (2007). HIV/AIDS health care policy and practice in Malaysia. In Leng, C. H. \& Barraclough, S. (ed) Health care in Malaysia: The dynamics of provision, financing and access 2007: p. 154-169.

[12] Liu H, Xu Y, Sun Y, Dumenci L (2014). Measuring HIV Stigma at the Family Level: Psychometric Assessment of the Chinese Courtesy Stigma Scales (CCSSs). PLoS ONE. 9 (3): e92855. doi: 10.1371/journal.pone.0092855.

[13] Choi P, Kavasery R, Desai MM, Govindasamy S, Kamarulzaman A, Altice F L (2010). Prevalence and correlates of community re-entry challenges faced by HIVinfected male prisoners in Malaysia. Int J STD AIDS. 21 (6): 416-423. doi: 410.1258/ijsa.2009.009180.

[14] Zelaya CE, Sivaram S, Johnson SC, Srikrishnan AK, Solomon S, Celentano DD (2008). HIV/AIDS Stigma: Reliability and Validity of a New Measurement Instrument in Chennai, India. AIDS Behaviour. 12 (5); 781-788. doi: 10.1007/s10461-0079331-7.

[15] Muturi N, An S (2010). HIV/AIDS Stigma and Religiosity Among African American Women. Journal of Health Communication. 15 (4): 388-401.

[16] Green G (1995). Attitudes Towards People With HIV: Are They As Stigmatizing As People With Hiv Perceive Them To Be? Social Science \& Medicine. 41 (4): 557-568. 
[17] Paruk Z, Mohamed SD, Patel C, Ramgoon S (2006). Compassion or condemnation? South African Muslim students' attitudes to people with HIV/AIDS. SAHARA-J: Journal of Social Aspects of HIV/AIDS. 3 (3): 510-515. doi: 10.1080/17290376.2006.9724878.

[18] Zimet GD, Dahlem NW, Zimet S, Farley GK (1988). The multidimensional scale of perceived social support. Journal of personality assessment. 52 (1): 30-41.

[19] Rosenberg M (1965). Society and the adolescent self-image. Princeton, NJ: Princeton University Press.

[20] Wright DO, Narr-King S, Lam P, Templin T, Frey M (2007). Stigma Scale Revised: Reliability and Validity of a Brief Measure of Stigma For HIV + Youth. Journal of Adolscenct Health. 40 (1): 96-98.

[21] Nachega JB, Lehman AD, Hlatshwayo D, Mothopeng R, Chaisson RE, Karstaedt AS (2005). HIV/AIDS and Antiretroviral Treatment Knowledge, Attitudes, Beliefs, and Practices in HIV-Infected Adults in Soweto, South Africa. Journal of Acquired Immune Deficiency Syndromes. 38 (2): 196-201.

[22] Savaser S (2003). Knowledge and attitudes of high school students about AIDS: A Turkish Perspective. Public Health Nursing. 20 (1): 71-79.

[23] Maimaiti N, Shamsuddin K, Abdurahim A, Tohti N, Memet R (2010). Knowledge, Attitude and Practice Regarding HIV/AIDS among University Students in Xinjiang. Global Journal of Health Science. 2 (2): 51-60.

[24] Ministry of Health (2015b). Global Aids Response Progress Report Malaysia. Available from: http://www.unaids.org/sites/default/files/country/documents/M YS_narrative_report_2015.pdf

[25] Meadowbrooke CC, Veinot TC, Loveluck J, Hickok A, Bauermeister JA (2014). Information Behavior and HIV Testing Intentions Among Young Men at Risk for HIV/AIDS. Journal of the Association for Information Science and Technology. $65 \quad$ (3): $\quad 609-620 . \quad$ doi: http://doi.org/10.1002/asi.23001

[26] Deblonde J, Hamers FF, Callens S, Lucas R, Barros H, Ruutel
$\mathrm{K}, \ldots$ Temmerman M (2014). HIV testing practices as reported by HIV-infected patients in four European countries. AIDS Care. 26 (4); 487-496. doi: 10.1080/09540121.2013.841831.

[27] Young SD, Hlavka Z, Modiba P, Gray G, Van Rooyen H, Richter L,.... Coates T (2010). HIV-related stigma, social norms, and HIV testing in Soweto and Vulindlela, South Africa: National Institutes of Mental Health Project Accept (HPTN 043). J Acquir Immune Defic Syndr, 55 (5),: 620-624. doi: 10.1097/QAI.0b013e3181fc6429.

[28] Maman S, van Rooyen H, Groves AK (2014). HIV status disclosure to families for social support in South Africa (NIMH Project Accept/HPTN 043). AIDS Care, 26 (2): 226-32.

[29] Wang X (2009). Integrating the Theory of Planned Behavior and Attitude Functions: Implications for Health Campaign Design. Health Communication, 24 (5): 426-434.

[30] Wang Y, Li B, Pan J, Sengupta S, Emrick CB, Cohen MS, Henderson GE (2010). Factors Associated with Utilization of a Free HIV VCT Clinic by Female Sex Workers in Jinan City, Northern China. AIDS Behav, 15 (4): 702-710. doi: 10.1007/s10461-010-9703-2.

[31] Beattie TS, Bhattacharjee P, Suresh M (2012). Personal, interpersonal and structural challenges to accessing HIV testing, treatment and care services among female sex workers, men who have sex with men and transgenders in Karnataka state, South India. J Epidemiol Community Health, 2012. 66 (suppl 2): 42-48.

[32] Kakoko DC, Astrom AN, Lugoe WL, Lie GT (2006). Predicting intended use of voluntary HIV counselling and testing services among Tanzanian teachers using the theory of planned behaviour. Soc Sci Med, 63 (4): 991-999. doi: 10.1016/j.socscimed.2006.02.016.

[33] Wong LP (2013). Multi-ethnic perspective of uptake of HIV testing and HIV-related stigma: A cross-sectional populationbased study. AIDS Care, 25 (11): 1356 - 1369. doi: 10.1080/09540121.2013.766302.

[34] Knussen C, Flowers P, McDaid LM (2014). Factors associated with recency of HIV testing amongst men residing in Scotland who have sex with men. AIDS Care, 26 (3): 297-303. doi: 10.1080/09540121.2013.824543. 